\title{
Identification of appropriate patients for preoperative evaluation: A quality improvement project
}

\author{
Terrence Trentman*1, Robert C. Graber ${ }^{2}$, Darin V. Goss ${ }^{3}$, Roshanak Didehban ${ }^{3}$, Susan G. Hagstrom ${ }^{4}$, Richard J. Fowl ${ }^{5}$ \\ ${ }^{1}$ Mayo Clinic, Arizona, United States \\ ${ }^{2}$ Department of Systems and Procedures, Mayo Clinic, Arizona, United States \\ ${ }^{3}$ Operations Administration, Mayo Clinic, Arizona, United States \\ ${ }^{4}$ Department of Anesthesiology, Mayo Clinic, Arizona, United States \\ ${ }^{5}$ Department of Surgery, Mayo Clinic, Arizona, United States
}

Received: October 23, 2015

DOI: $10.5430 /$ jha.v5n2p73
Accepted: January 7, 2016

URL: http://dx.doi.org/10.5430/jha.v5n2p73

\begin{abstract}
Objective: Appropriate preoperative evaluation is essential for safe surgical care. Cost containment and "best practice" suggest that preoperative testing should be matched to patient co-morbidities and the magnitude of the planned procedure. The purpose of this project was to reduce the number of unnecessary referrals to our preoperative evaluation clinic (POE), increase clinic capacity for medically complex patients including diabetics, and quantify the reduction in institutional cost associated with the project. Methods: In addition to other educational activities, a simplified algorithm and optional screening tool were created to assist surgeons with determining which patients should go to POE. A sub-group of pilot surgeons were selected to participate and their POE referral performance was tracked and shared with them. Surgeons were encouraged to send all of their diabetic patients through POE. A cost analysis was carried out to quantify changes in institutional average cost per case for preoperative evaluation, before $v s$. after project launch. The first quarter of 2013 (pre-project launch) was compared to first quarter 2015.

Results: Pilot surgeons reduced referrals to POE by $30 \%$, while decreasing the institutional average cost per case of preoperative evaluation by $>50 \%$. Clinic capacity for complex patients increased, although diabetic referrals remained flat during the project. There was no increase in day of surgery cancellations.

Conclusions: This project demonstrates that patterns of preoperative evaluation for healthy patients undergoing low-acuity surgery can be changed, bringing about cost savings, without increasing day of surgery cancellations.
\end{abstract}

Key Words: Cost savings, Preoperative evaluation, Diabetes, Bundled payments

\section{INTRODUCTION}

Appropriate preoperative evaluation is essential for safe surgical and anesthesia care. At a minimum, the preoperative evaluation consists of a history and physical exam performed by the surgeon or advanced midlevel provider. In some cases, the preoperative exam includes cardiac, pulmonary and other subspecialty consultations and costly invasive testing. Sur- geons and anesthesiologists may differ in opinion regarding necessary preoperative testing. This may result in delays and frustration as blood draws, chest x-rays or electrocardiograms are obtained "last minute". Surgeons may respond by over-ordering preoperative studies in an effort to satisfy the most demanding anesthesiologist to prevent cancellation or delay of a case.

*Correspondence: Terrence Trentman; Email: Trentman.Terrence@ mayo.edu; Address: Mayo Clinic, Arizona, United States. 
Simultaneously, both cost containment efforts and the principles of "best practice" suggest that preoperative testing should be thoughtfully matched to patient co-morbidities and the magnitude of the planned procedure. In an environment of bundled payments, unneeded preoperative testing erodes the profit margin of the organization.

Growing awareness of the risks and costs of unnecessary preoperative testing has resulted in guidelines which are based on clinical indicators and factors. One example of these guidelines is that preoperative testing is unnecessary for healthy patients undergoing low-acuity procedures. ${ }^{[1-3]}$ Nonetheless, at our institution we observed that preoperative testing and referrals to our preoperative evaluation clinic (POE) have historically been driven more by practice patterns and surgeon preference than adherence to guidelines, i.e. some surgeons send almost every patient to POE regardless of the procedure, and some send almost no patients to the clinic. Unnecessary POE referrals waste resources and decrease clinic capacity to see medically complex patients undergoing higher risk surgery.

In order to improve the efficient use of our preoperative clinic, we embarked on a multi-disciplinary pilot project to educate our surgeons on appropriate POE referrals and preoperative testing. In the process, we created screening tools for surgeons to assist them in identifying appropriate patients for formal evaluation in POE. Since we expected that this project would increase POE capacity, an effort was undertaken to increase the number of (preoperative) diabetic patients seen in the clinic as part of a larger institutional glycemic control initiative.

Therefore, the purpose of this pilot project was to: (1) Reduce the number of healthy (American Society of Anesthesiologists [ASA] physical status 1-2) outpatients referred to POE clinic; (2) Increase the number of diabetic patients referred to the clinic; (3) Track all day-of-surgery cancellations related to the preoperative evaluation; and (4) Quantify changes in institutional cost for preoperative evaluation before versus after the project launch. In this report, we will also describe the educational effort necessary to bring about these changes.

\section{MethodS}

\subsection{Project design and setting}

This non-interventional, quality improvement project was deemed exempt from Institutional Review Board review. The multi-disciplinary team was formed in mid-2013 and consisted of representatives from surgery (RF), anesthesiology (TT) and internal medicine/POE (SH). Additional support from Administration (RD, DG) and Systems and Procedures (BG) was provided. Our institution is an academic medical center with a closed staff of approximately 450 physicians.

\subsection{Educational tools}

The work group determined that the project would focus on minimizing referrals to POE for healthy patients (defined as ASA Class 1-2), undergoing low-acuity outpatient surgery. Preoperative evaluation would still be expected for intermediate and high risk procedure patients regardless of ASA Class. Typical low-acuity surgeries included distal extremity (hand, foot and ankle), breast and skin procedures, endoscopic and minor urologic or otolaryngologic operations.

An early step was to create a simplified algorithm to assist surgeons with determining which patients should be referred to POE (see Figure 1). Subsequently, the surgical practice was encouraged to send all diabetic patients to POE regardless of ASA class, even if they were undergoing outpatient surgery.

Next, the definitions of ASA 1 and 2 were shared with the surgeons via e-mail and meetings with departments. An optional screening tool was also developed and shared for use in surgery clinics in an effort to assist surgeons and their staff to identify higher acuity patients that would require preoperative evaluation (see Figure 2). The screening tool could be filled out by the patient and briefly reviewed by the surgeon or assistant. Answers in the "gray boxes" would trigger further questions to confirm the severity of the condition in question. If the patient had significant medical issues, referral to POE was encouraged. Additionally, surgeons were educated that for low acuity patients only diagnostic testing required for surgical care should be considered: no testing was recommended related to anesthesia care.

In addition to the screening tool, we created a history and physical "Power Note" in our electronic medical record. The surgeons and their mid-level providers were invited to use the note to complete the required preoperative history and physical, if they did not send their patient to POE.

\subsection{Sample selection}

To test our assumptions, we selected 8 volunteer surgeons and their support staff to pilot this new process (among a staff of approximately 60 surgeons). The pilot surgeons represented departments and practices that frequently perform low-acuity procedures on outpatients, including General Surgery, Gynecology, Hand Surgery, Urology and Otolaryngology. No surgeon declined the invitation to participate.

During the pilot phase, a number of metrics were tracked and shared with the surgeons, including the percentage of POE consults for ASA 1-2 patients undergoing outpatient procedures; comparison of ASA 1-2 patients being sent to 
POE from pilot surgeons $v s$. the remaining surgical practice, was carried out to compare institutional costs (not merely and number of diabetic patients sent to POE. As a counter measure, we also tracked day of surgery cancellations before charges) to evaluate these patients before surgery, before versus after the pilot program was launched. and after the launch of the project. Finally, a cost analysis

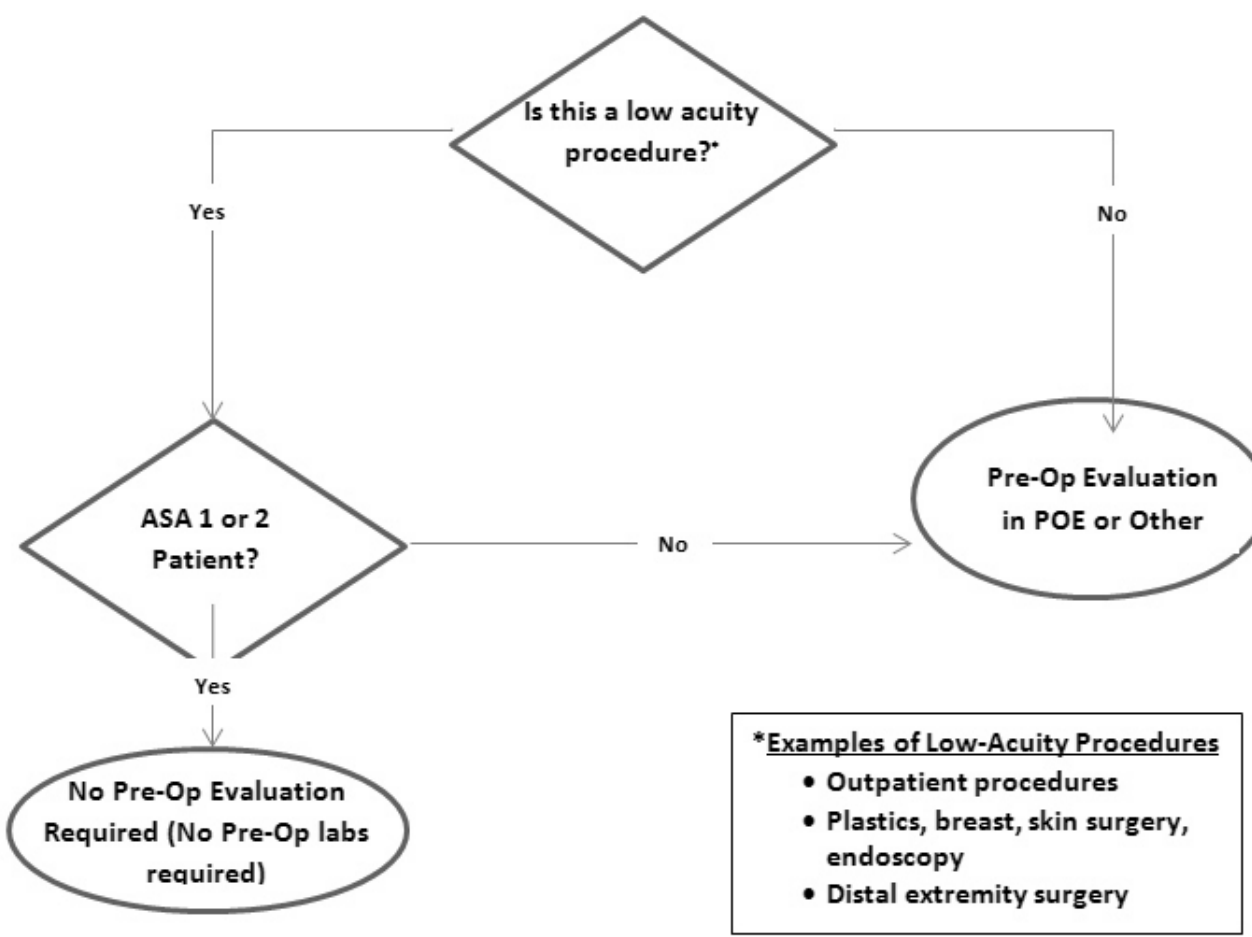

\begin{tabular}{|l|l|l|}
\hline $\begin{array}{l}\text { ASA } \\
\text { PS 1 }\end{array}$ & $\begin{array}{l}\text { Normal healthy } \\
\text { patient }\end{array}$ & $\begin{array}{l}\text { No mental or physical health problems; does not include patients at extremes of age. } \\
\text { Good exercise tolerance }\end{array}$ \\
\hline $\begin{array}{l}\text { ASA } \\
\text { PS 2 }\end{array}$ & $\begin{array}{l}\text { Patients with } \\
\text { mild systemic } \\
\text { disease }\end{array}$ & $\begin{array}{l}\text { Minimal or no functional limitations. Disease of one body system that is well } \\
\text { controlled, e.g. smoking but no chronic obstructive pulmonary disease (COPD), } \\
\text { well controlled diabetes or hypertension, pregnancy, mild obesity }\end{array}$ \\
\hline $\begin{array}{l}\text { ASA } \\
\text { PS 3 }\end{array}$ & $\begin{array}{l}\text { Patients with } \\
\text { severe systemic } \\
\text { disease }\end{array}$ & $\begin{array}{l}\text { Has functional limitation(s); controlled disease of > one body system; no } \\
\text { immediate danger of death; } \text { e.g. controlled congestive heart failure (CHF), angina, } \\
\text { hypertension, morbid obesity, renal failure; reactive airway disease }\end{array}$ \\
\hline
\end{tabular}

$\mathrm{POE}=$ Preoperative evaluation clinic; ASA PS = American Society of Anesthesiologists Physical Status

Figure 1. Algorithm for POE referrals

Table adapted from ASA Physical Status definitions and examples. Available from:

http://www.asahq.org/resources/clinical-information/asa-physical-status-classification-system

\subsection{Statistical analysis}

The data was analyzed with simple descriptive statistics including percentages and percent change. The Fisher's exact test was used to compare proportions of patients sent to POE, baseline vs. follow up. A $p$-value $<.05$ was considered significant. Comparison periods selected were first quarter 2013, before the project began versus $1^{\text {st }}$ quarter 2015, after education and practice changes had occurred. Our cost data is analyzed internally, using commercial software (EPSi, Allscripts ${ }^{\mathrm{TM}}$ Chicago, IL USA).

\section{RESULTS}

\subsection{Baseline data}

At baseline during the first quarter 2013, approximately 35\% of patients referred to POE by the overall surgical practice were considered low risk, i.e. the patients were subsequently given an ASA physical status of 1 or 2 . In contrast, the pilot surgeons were found to be sending 55\% of their low-acuity, outpatients to POE. At re-measurement during the first quarter 2015 , only $25 \%$ of the low-acuity patients from these surgeons were sent to the preoperative clinic, $p<.0001$ (see Figure 3). 
MAYO Medical History Questionnaire

ED

Number (above) and Name

\begin{tabular}{|c|c|c|}
\hline & Yes & No \\
\hline $\begin{array}{l}\text { In the past } 3 \text { months, have you had any changes in the following conditions (including new medications): } \\
\text { New or worsening shortness of breath? } \\
\text { New or worsening light-headedness or fainting? } \\
\text { New or worsening chest tightness, pressure or pain? } \\
\text { Worsening of angina? }\end{array}$ & $\begin{array}{l}\square \\
\square \\
\square \\
\square\end{array}$ & $\begin{array}{l}\square \\
\square \\
\square \\
\square\end{array}$ \\
\hline In the last 3 months, have you been seen in the emergency room or admitted to the hospital? & $\square$ & $\square$ \\
\hline $\begin{array}{l}\text { In the last } 3 \text { months, have you seen a primary care provider (PCP) for a complete medical exam? } \\
\text { If yes, please provide name of } \mathrm{PCP}\end{array}$ & $\square$ & $\square$ \\
\hline Can you climb a flight of stairs without becoming short of breath or stopping? & $\square$ & $\square$ \\
\hline Can you walk at least 2 blocks? & $\square$ & $\square$ \\
\hline Can you lie flat? & $\square$ & $\square$ \\
\hline Do you feel short of breath when you lie flat? & $\square$ & $\square$ \\
\hline
\end{tabular}

\begin{tabular}{|c|c|c|}
\hline Have you had a history of any of the following: & Yes & No \\
\hline Heart trouble. If yes, explain & $\square$ & $\square$ \\
\hline $\begin{array}{l}\text { Have you ever undergone coronary stent placement? } \\
\text { If yes, year this was done }\end{array}$ & $\square$ & $\square$ \\
\hline Pacemaker or defibrillator implanted? & $\square$ & $\square$ \\
\hline Have you ever had a stroke or TIA? & $\square$ & $\square$ \\
\hline Nervous disorder. If yes, explain & $\square$ & $\square$ \\
\hline $\begin{array}{l}\text { Lung disease (asthma, emphysema, COPD) } \\
\text { Have you had a respiratory infections with fever in the past } 4 \text { weeks? } \\
\text { Do you use oxygen at home? }\end{array}$ & $\begin{array}{l}\square \\
\square \\
\square\end{array}$ & $\begin{array}{l}\square \\
\square \\
\square\end{array}$ \\
\hline $\begin{array}{l}\text { Diabetes complications (such as diabetic ketoacidosis, difficulty controlling blood sugar (high or low levels), frequent hypoglycemia). } \\
\text { If yes, explain }\end{array}$ & $\square$ & $\square$ \\
\hline Kidney disease (with the exception of kidney stone disease) & $\square$ & $\square$ \\
\hline Gastrointestinal disease (liver/cirrhosis) & $\square$ & $\square$ \\
\hline $\begin{array}{l}\text { Bleeding tendencies (bleeding or bruising easily) } \\
\text { Blood clots }\end{array}$ & $\begin{array}{l}\square \\
\square\end{array}$ & $\square$ \\
\hline Do you take blood thinners other than aspirin (plavix, coumadin/warfarin, pradaxa, rivaroxaban, lovenox)? & $\square$ & $\square$ \\
\hline
\end{tabular}

\begin{tabular}{|l|c|c|}
\hline Your experience with Anesthesiology & Yes & No \\
\hline $\begin{array}{l}\text { Have you or a blood relative had trouble with anesthesia (other than nausea, slow to wake-up or sore throat)? This includes } \\
\text { malignant hyperthermia or difficult aimway. }\end{array}$ & $\square$ \\
If yes, explain & $\square$ & $\square$ \\
$\begin{array}{l}\text { Do you have any particular concerns regarding anesthesia? } \\
\text { If yes, explain }\end{array}$ & $\square$ \\
\hline \multicolumn{1}{|c|}{ Note to provider: please contact Anesthesiology directly if no POE or PCP consultation. } & $\square$ \\
\hline
\end{tabular}

Figure 2. Medical Questionnaire used as a screening tool to assist with POE determination 


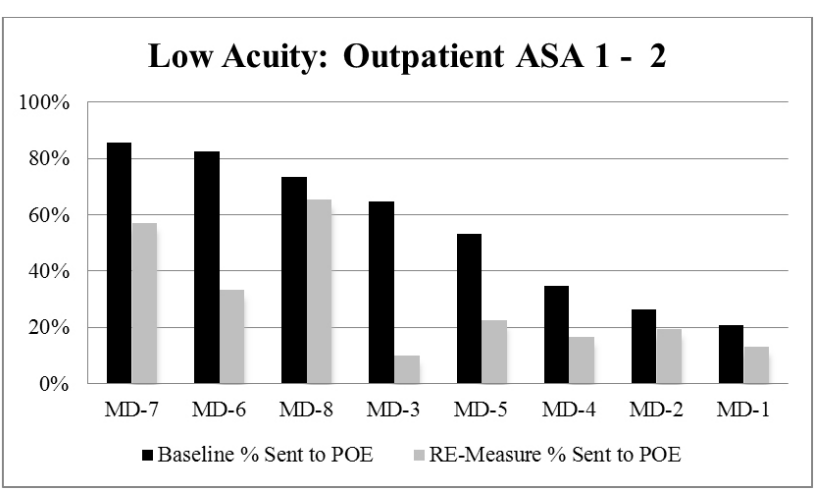

Figure 3. Change in $\%$ of patients sent to POE, by pilot surgeon, before and after initiation of pilot program POE: Preoperative Evaluation Clinic; ASA: American Society of Anesthesiologists Physical Status; MD: medical doctor

\subsection{Cost comparison and outcomes}

An analysis was performed to compare average institutional cost per case for preoperative evaluation of the patients, before and after project launch. Costs included the expense of the provider plus any preoperative testing such at Electrocardiograph (ECG), chest $x$-rays or laboratory work. During the relevant time periods, there were no significant changes in institutional costs due to external factors or internal processes, other than normal increases in cost related to inflation. Further, there were no changes in hospital policies or procedures during this time that would account for differences in average cost per case.

As shown in Table 1, both the numbers of ASA 1-2 patients sent to POE by the pilot surgeons and the associated costs dropped dramatically. Not only did the number of patients sent to POE decrease, but the average cost per case of evaluating those not sent to POE also decreased, suggesting that the surgeons were ordering fewer preoperative tests on these patients.

There was no increase in cancellations after implementation of the project. There were 5 same-day cancellations during the baseline period in 2013, and 5 cancellations in 2015 .

Finally, the percent of diabetic patients sent to POE by the overall surgical practice was $62 \%$ in both the $1^{\text {st }}$ quarter 2013 and the $1^{\text {st }}$ quarter 2015. However, in August 2015 diabetic referral to POE increased to $75 \%$.

Table 1. Cost comparison of patients sent to POE by pilot surgeons

\begin{tabular}{|c|c|c|c|c|}
\hline \multicolumn{2}{|c|}{ Baseline: $1^{\text {st }}$ Quarter 2013} & \multicolumn{2}{|c|}{ Re-Measure: $1^{\text {st }}$ Quarter 2015} & \multirow{2}{*}{$\begin{array}{l}\text { Result } \\
\% \text { Change in average cost per case }\end{array}$} \\
\hline POE Visit? & No. of Patients & POE Visit? & No. of Patients & \\
\hline No & 154 & No & 243 & $-51.0 \%$ \\
\hline Yes & 138 & Yes & 66 & $-3.7 \%$ \\
\hline Total & 292 & Total & 309 & $-53.0 \%$ \\
\hline
\end{tabular}

Note. Cost comparison of patients sent to POE (preoperative evaluation clinic) before and after process improvement project. All patients were scheduled for outpatient surgery and were judged to be American Society of Anesthesiologist's (ASA) physical status 1 or 2. Average cost per case based upon preoperative provider visit and any preoperative studies including blood count and chemistry, electrocardiogram and chest $x$-ray.

\section{Discussion}

A substantial body of literature establishes the lack of benefit and increased cost associated with routine preoperative testing in stable patients undergoing low- and moderate-acuity surgery. ${ }^{[3,4]}$ Further, this testing seldom changes management. ${ }^{[5]}$ Despite recommendations from the ASA, the American College of Cardiology and the American Board of Internal Medicine Foundation (Choose Wisely Campaign ${ }^{\mathrm{TM}}$ ), patients are still routinely sent for preoperative "clearance" by primary care providers, internists and preoperative clinics like ours. In an environment of shrinking reimbursement and bundled payments, avoiding unnecessary preoperative testing and clinic visits makes economic sense. Furthermore, patient satisfaction can be increased with fewer preoperative tests and appointments, which may only serve to increase their out-of-pocket expenses and delay the scheduling of their procedure. Unfortunately, there is relatively little information on how to bring about physician behavioral changes.
This project was not about establishing the futility and waste of preoperative consultations and studies. Instead, it demonstrates a process to bring about changes in the referral patterns of proceduralists. We began with education of the surgical practice, and then added decision making tools. Altering long-held beliefs and practice patterns requires multiple forms of communication and practice management aids, to ensure both understanding and continued practice efficiency. This quality project documents a substantial reduction, although not an elimination, of unnecessary preoperative referrals.

In a survey study of preoperative clinic directors, anesthesiologists, gynecologists, general surgeons and orthopedists, anesthesiologists were less likely than the other specialists to order unnecessary preoperative tests. ${ }^{[6]}$ However, unnecessary ordering of tests was still common among the anesthesiologists, with $46 \%$ of them ordering at least one unnecessary 
test. While it has been shown that institutional guidelines can reduce unnecessary test ordering, ${ }^{[7-9]}$ the practice and "habit" of routine testing is widespread and costly.

Surgeons may refer patients for preoperative evaluation to reduce their own work load, i.e. another provider will complete the required history and physical exam and make decisions about testing. Physicians may order testing out of fear of medical-legal risk, habit, misunderstanding over best practice, institutional requirements, or to prevent delays and cancellations on the day of surgery. ${ }^{[10]}$ It's noteworthy that in our study, no increase in day of surgery cancellations was seen.

Using Medicare inpatient claims data, Sheffield et al. found that $3.75 \%$ of patients with no cardiac indications for preoperative stress testing underwent such testing within 2 months of general surgical, urologic or orthopedic surgery. ${ }^{[11]}$ The rate of this unnecessary testing increased from $1.72 \%$ in 1996 to $6.44 \%$ in 2007 ( $p<.0001)$. Patients who lived in areas of greater Medicare spending were more likely to undergo unnecessary cardiac stress testing.

Czoski-Murray et al. used a literature review to estimate the clinical and cost effectiveness of routine testing in healthy (ASA 1-2) surgical patients undergoing minor or intermediate acuity procedures. ${ }^{[4]}$ Their review covered the time period 1980 forward, and found that while a paucity of literature exists to answer these questions, there is a lack of robust data to support use of preoperative tests in this patient population.

In the current economic environment, this project could potentially harm the institution's financial performance since clinic visits and testing generate revenue. However, in a future bundled payment model, it makes economic sense to expend resources only where they are needed. Our study has shown that costs can be decreased dramatically, not only for patients seen in POE but also for those not sent for preopera- tive evaluation. We believe the reduced costs are a result of provider education regarding appropriate testing before low acuity surgery in healthy patients; namely, don't test!

\section{Limitations}

Weaknesses of our project include the relatively small number of patients followed in total and per specialty, and lack of data on any surgical delays (but not cancellations) related to patients not seen in POE. We also did not quantify any lost revenue due to elimination of POE visits and preoperative testing, or any complications that might have resulted due to a lack of a POE visit. A private hospital might view these clinic visits and testing as a revenue stream and be disincentivized to change their practice.

Our results also illustrate the difficulty in changing referral patterns for the overall surgical practice: diabetic referrals to POE did not change dramatically from baseline, although the August 2015 performance was positive. Finally, we don't have data on long or short-term benefits of sending more diabetic patients to POE, including diabetics. As a next step, we are analyzing the impact of this project on our larger surgical practice.

\section{Conclusions}

This pilot project demonstrates that patterns of preoperative evaluation for healthy patients undergoing low-acuity surgery could be changed without increasing day of surgery cancellations. Simultaneously we reduced average institutional cost per case for preoperative evaluation by more than $50 \%$. An added benefit was increasing POE capacity for more medically complex patients including diabetics. Although it is well-known that unnecessary preoperative testing is common, changing referral patterns is difficult. Our data suggest that a multi-disciplinary educational process, practice support tools and ongoing performance monitoring can bring about lasting changes.

\section{REFERENCES}

[1] Kumar A, Srivastava U. Role of routine laboratory investigations in preoperative evaluation. Journal of anaesthesiology, clinical pharmacology. 2011; 27: 174-179. http://dx.doi.org/10.4103/097 $0-9185.81824$

[2] Apfelbaum JL, Connis RT, Nickinovich DG, et al. Practice advisory for preanesthesia evaluation: an updated report by the American Society of Anesthesiologists Task Force on Preanesthesia Evaluation. Anesthesiology. 2012; 116: 522-538. http://dx.doi.org/10.10 97/ALN . Ob013e31823c1067

[3] Chung F, Yuan H, Yin L, et al. Elimination of preoperative testing in ambulatory surgery. Anesthesia and analgesia. 2009; 108: 467-475. http://dx.doi.org/10.1213/ane.0b013e318176bc19

[4] Czoski-Murray C, Lloyd Jones M, McCabe C, et al. What is the value of routinely testing full blood count, electrolytes and urea, and pulmonary function tests before elective surgery in patients with no apparent clinical indication and in subgroups of patients with common comorbidities: a systematic review of the clinical and costeffective literature. Health technology assessment. 2012; 16: i-xvi, 1-159. http://dx.doi.org/10.3310/hta16500

[5] Bryson GL, Wyand A, Bragg PR. Preoperative testing is inconsistent with published guidelines and rarely changes management. Canadian journal of anaesthesia = Journal canadien d'anesthesie. 2006; 53: 236-241. http: //dx.doi.org/10.1007/BF03022208 
[6] Katz RI, Dexter F, Rosenfeld K, et al. Survey study of anesthesiologists' and surgeons' ordering of unnecessary preoperative laboratory tests. Anesthesia and analgesia. 2011; 112: 207-212. http: //dx.doi.org/10.1213/ANE.0b013e31820034fo

[7] Ferrando A, Ivaldi C, Buttiglieri A, et al. Guidelines for preoperative assessment: impact on clinical practice and costs. International journal for quality in health care: journal of the International Society for Quality in Health Care/ISQua. 2005; 17: 323-329. http://dx.doi.org/10.1093/intqhc/mzi039

[8] Larocque BJ, Maykut RJ. Implementation of guidelines for preoperative laboratory investigations in patients scheduled to undergo elective surgery. Canadian journal of surgery. Journal canadien de chirurgie. 1994; 37: 397-401.

[9] Mancuso CA. Impact of new guidelines on physicians' ordering of preoperative tests. Journal of general internal medicine. 1999; 14 166-172. http://dx.doi .org/10.1046/j.1525-1497.1999.0 $0308 . x$

[10] Brown SR, Brown J. Why do physicians order unnecessary preoperative tests? A qualitative study. Family medicine. 2011; 43: 338-343. PMid: 21557104.

[11] Sheffield KM, McAdams PS, Benarroch-Gampel J, et al. Overuse of preoperative cardiac stress testing in medicare patients undergoing elective noncardiac surgery. Annals of surgery. 2013; 257: 73-80. http://dx.doi.org/10.1097/SLA. Ob013e31826bc2f4 